\title{
Managed Annihilation: An Unnatural History of the Newfoundland Cod Collapse
}

By D. Bavington. 2010. UBC Press, 2029 West Mall, Vancouver, British Columbia V6T 1Z2. 186 pages. 85.00 CAD. Paper.

The mismanaged cod stocks off Newfoundland make for a global monument in time. But by now it's also a feast for environmental writers both local and far away. This book by D. Bavington is one of those books, and it must 'swim among its competitors'. I find, it barely floats.

The Foreword by G. Wynn ("This Is More Difficult Than We Thought") makes for an impressive standalone read though. The subsequent 8 chapters then continue to re-tell us the story we all know (and which many "lived"): A super abundant fish with a complex and fascinating life history and of huge cultural value (like most other fish and natural renewable resources, for that matter) went lost. The book then moves into a governmental and apologetic view, elaborates on selforganizing, holarctic and open (SOHO) systems, presents a great review of 'how cod is killed', shows aspects of managing fish and fishermen, displays some rarely discussed issues of cod farming ("egg to plate"; as promoted by the Norwegians and politicians), and from there gives eventually common conclusions: the government messed it up, the resource and its culture is destroyed for good, but nobody is personally to blame (a widely found Canadian tradition that results in a national blur and public guilt). I find that the book falls somewhat short though on the implied promise of its catchy title (it does not really cover the failure of the individual managers, and the management-science brotherhood).

People new to this subject will still find the facts and details provided refreshing perhaps, e.g., that China is processing shrimp from Newfoundland, the 'underutilized species' fisheries for krill and jellyfish, and also that many of the inshore bays were (locally) over-fished since the 18th century. But an audience of Canadian naturalists and fishermen who know the situation locally, or from similar experience elsewhere, might be less enthused with this text. The social science perspective might be interesting to some, but the wordy and lengthy style without too much hard facts is annoying to others. In times like this, and as naturalists, perhaps we must be grateful for anything that is not a resource-destroying propaganda? The role of scientists gets widely delivered in the text, but it leaves 
out the infighting and humiliation of "the researchers and experts that actually suffered" but who were not in the spotlight such as the now celebrated Ram Myers and Jeff Hutchison. Of course, in a book like this, Maximum Sustainable Yield (MSY), the infamously disastrous Beverton and Holt curves, and the tragic ITQ and TAC quota systems are discussed, as well as the impact of international fisheries. 'Jiggers', proceduralism, and the royal crown and Canadanisation are mentioned too. The efforts by the Norwegian fisheries expert Adolph Nielsen in 1889 on Dildo Island provides for an informative lesson in fisheries history.

The question whether to fish for money or for food makes for a central scheme indeed, and is of global relevance. Granted, the author makes the brilliant point that leisure fishing for cod is now basically illegal (!"Criminalization of fishing as a way of life"). The elaborations of political and imperial ecology provide a nice new and needed angle in the public discussion. For instance the statement that "management - an idea rooted in the political and economic context of capitalistic resource extraction" still needs to be understood by many. The same is true for the fact that "Fisheries science, technology, and management have all been aimed at creating and sustaining this context of capitalist resource extraction by transforming fisheries around the world into an industrial sector". Management comes with a political and business ideology, and which does not consider, nor mix with, wilderness and natural resources. Personally, I also like the accumulation of human impact and ethics literature references and footnotes (among one of the best on the cod issue). The index is crisp but helpful; 2 pages of abbreviations are included. Cartoons, figures and many quotes are presented, e.g., the one made by J.R. Saul: "Management is a tertiary skill - a method, not a value. And yet we apply it to every domain as if it were the ideal of our civilization", or by M. Parker "More than any other form of knowing or practice, management is claimed to be absolutely nomadic and universally useful".

The notion of "success through failure" must come as a cynical and inappropriate view and considering all the loss our nature, society and the oceans went through. Neither climate change nor UNCLOS, or offshore oil and gas exploration (or chronic oil spills) are covered in this book though. Corruption is kindly ignored once more ("Once the stock status was agreed upon, TAC levels were secretly negotiated by DFO officials and hand-picked representatives from the fishing industry"). It's too bad that no true institutional, legal and economic change was requested by the author. Institutions like ICES, NAFO, ICNAF and certainly DFO, and global seafood processing corporations got away with the murder of fish and a fishery. This book barely delivers on the DFO problem; the role of our banking system gets ignored. And we all still eagerly wait for a documented public review of the Memorial University of Newfoundland (MUN) and its role in the 'cod game'.

The Newfoundland fisheries were one of the mostadvanced and well-funded fisheries, and with a huge science-base right before it crashed to commercial extinction. Many know the infamous citation by $\mathrm{R}$. de Soncino (London 18 Dec. 1497): "The sea is covered with fish which are caught not merely with nets but with baskets". But too bad that most ignore that our western regime and lifestyle, the assumed manageability of the world, resulted in "an ecological crime comparable to the Soviet Union's draining of the Aral Sea" (and as also stated in this book). Which ideology really is better for the natural resource and the world?

In conclusion, this book adds some new views, but has many competitors in the published landscapes. It adds to the long and tragic list of existing and forthcoming environmental history publications in Canada and the western world. Canada has unfortunately much to write about and more is in stock. The author confirms what we already all know: a poor (Canadian) governance and one that is bought out by other interest than food, fishermen and long-term sustainability, sets us all up for global bankruptcy (the type we just experience in 2011). It's time to change dogmas, again.

FalK HuEtTManN

Institute of Arctic Biology, Biology \& Wildlife Department, University of Alaska-Fairbanks (UAF), Fairbanks Alaska 99775 USA 